\title{
Analysis of Undercut for SS304 in Photochemical Machining
}

\author{
S. Yadav $^{1 *}$, A. Saraf ${ }^{2}$, M. Sadaiah ${ }^{3}$ \\ ${ }^{1}$ U.G. Student, ${ }^{2}$ Research Scholar, ${ }^{3}$ Associate Professor \\ ${ }^{1,2,3}$ Dr. Babasaheb Ambedkar Technological University, Lonere,Raigad, India. \\ \{spyadav@dbatu.ac.in\}
}

\begin{abstract}
Undercut plays a crucial role in the industry of photochemical machining technology. This paper inspects the effect of undercut on the process parameter in Photochemical Machining (PCM) of SS304. A full factorial $\left(3^{3}\right)$ Design of Experiments (DoE) were performed consisting of twenty-seven experimental runs. The concentration of etchant, temperature and time of etching were assumed to be the control parameters whereas the undercut $(\mathrm{Uc})$ was considered to be the response parameter. Analysis of Variance (ANOVA) technique was used to analyze the effect of control parameters on undercut and thus the evaluation of its optimal conditions were performed. The experimental investigations revealed that the temperature of etchant and time of etching are the most substantial factors affecting the undercut.
\end{abstract}

Keywords: photochemical machining, undercut, SS304, ANOVA, DoE

\section{Introduction}

The production of burr and stress free components through non-conventional machining processes of flat metal is possible by Photochemical Machining (PCM) technique. The machining employs usage of a strong chemical solution contact for the controlled dissolution of workpiece material. The industry of PCM at present plays a crucial role in the manufacturing of a range of precision parts viz. copper printed circuit boards, silicon based integrated circuits, channels for the flow of micro fluid and decorative items. In the field of electronics, aerospace and medical it is used for manufacturing of micro components. Chemical etching method through a photoresists stencil material is used for removal of material over selected areas. It is relatively modern technique and gaining establishment in manufacturing process. The development of new products from PCM are especially applicable to micro-engineering, microfluidics and microsystem technology.

The imperative material used currently in biomedical and chemical industry for various engineering applications and specialty is SS304. The most commonly used etchant is aqueous $\mathrm{FeCl}_{3}$. Very few literature is available on photochemical machining of SS304. In the literature, (Cakir 2007) found that ferric chloride $\left(\mathrm{FeCl}_{3}\right)$ which acts as a suitable etchant for aluminium etching [7]. The chemical reaction is simple, making the process easy to control. He studied copper etching with cupric chloride $\left(\mathrm{CuCl}_{2}\right)$ etchant with simultaneous of the waste etchant [5-6]. Etching process is used to make the overall manufacturing cost economical and a more environmentally friendly. (Allen \& Almond 2004) studied the characterization of aqueous ferric chloride etchants used in industrial PCM [1-3] [9]. There are a variety of grades of $\mathrm{FeCl}_{3}$ but this is the most commonly used etchant. (Roy et al. 2004) investigated a cost model to analyze and monitor them for PCM which defines standards for industrial etchants and methods [4]. (Allen 1983) studied the manufacture of stainless steel edge filters: an application of electrolytic photo polishing and stated two methods for manufacturing of an edge filter [8]. Also the surface textures and process characteristics of the electrolytic photoetching of annealed AISI304 stainless steel in hydrochloric acid was studied [10-13]. (Muhl \& George 1995) studied direct printing of etch masks under computer control in which all the stages of photo-processing and mask making [2]. (Saraf \& Sadaiah 2013; Liu et al. 2005) developed an artificial neural network model for the etching process [14-19]. The manufacture of WC micro-shaft by using electrochemical etching was investigated by (Choi et al. 2006). The mathematical model of liquid membrane electrochemical etching of a Nano tip was studied by (Wu et al. 2013) [5-7].

B. Iyer, S. Nalbalwar and R. Pawade (Eds.)

ICCASP/ICMMD-2016. Advances in Intelligent Systems Research.

Vol. 137, Pp. 284-289.

(C) 2017. The authors - Published by Atlantis Press

This is an open access article under the CC BY-NC license (http://creativecommons.org/licens)es/by-nc/4.0/). 
From literature, it has been reported that for analyzation of the interaction effects of process parameters on etching process of SS304 there is no statistical studies involved. An accuracy of PCM depends only on the skill and experience of the operator till date. Work to date an optimal set of process parameters is not calculated.

For investigation of the performance in different ranges as well as to find the global optimum process parameters thestatistical study is necessary. To satisfy the requirements of excellent etching quality it is also necessary to find out the single optimum process parameters setting. An ANOVA technique which is full factorial design method is attempted for this work to study the optimum process parameters.

\section{Experimental procedure}

$\mathrm{FeCl}_{3}$ is used as an etchant in the experiment for machining of SS 304. The composition of the material is shown in Table 1.

Table 1 Chemical composition of stainless steels 304

\begin{tabular}{|l|l|l|l|l|l|l|l|l|}
\hline Grade & $\mathrm{C}$ (Max) & $\mathrm{Cr}$ & $\mathrm{Mn}$ & $\mathrm{Si}$ & $\mathrm{Mo}$ & $\mathrm{N}$ & $\mathrm{P}$ & $\mathrm{S}$ \\
\hline SS304 & 0.08 & 18.46 & 2 & 0.75 & 2.15 & 0.10 & 0.045 & 0.030 \\
\hline
\end{tabular}

The concentration of $\mathrm{FeCl}_{3}$ solutions were prepared at 650, 750 and $850 \mathrm{~g} / \mathrm{l}$ respectively. The amount of etchant for each experiment was $4500 \mathrm{ml}$. The schematic representation of the experimental setup used for the experimentation is shown in fig. 1

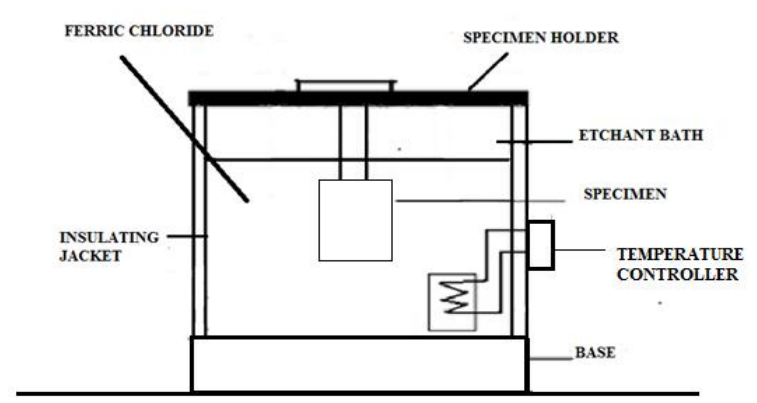

Fig. 1. Schematic diagram of Experimental set-up for etching

Photochemical machining tests were performed at $45^{\circ} \mathrm{C}, 55^{\circ} \mathrm{C}$ and $65^{\circ} \mathrm{C}$. The process used was a single-sided chemical etching during which the temperature was maintained within a range of $\pm 1^{\circ} \mathrm{C}$. The chemical etching periods were 90, 150, and 220 minutes. In order to understand the process parameter interactions the following Design of Experiment (DoE) technique was used. Each parameter is assigned to have three levels namely low, medium and high respectively (Number of treatment conditions $=3^{\mathrm{k}}=3^{3}=27$ ) using full factorial DoE technique. Experimental design matrix is shown in Table 2.

Table 2 Experimental Design Matrix

\begin{tabular}{|l|l|l|l|}
\hline Sr.No. & Temperature $\left(\mathbf{~}^{\mathbf{C}}\right)$ & Concentration $(\mathbf{g} / \mathbf{l})$ & Time \\
\hline 1 & 45 & 650 & 90 \\
\hline 2 & 45 & 650 & 150 \\
\hline 3 & 45 & 650 & 220 \\
\hline 4 & 45 & 750 & 90 \\
\hline 5 & 45 & 750 & 150 \\
\hline 6 & 45 & 750 & 220 \\
\hline 7 & 45 & 850 & 90 \\
\hline
\end{tabular}




\begin{tabular}{|l|l|l|l|}
\hline 8 & 45 & 850 & 150 \\
\hline 9 & 45 & 850 & 220 \\
\hline 10 & 55 & 650 & 90 \\
\hline 11 & 55 & 650 & 150 \\
\hline 12 & 55 & 650 & 220 \\
\hline 13 & 55 & 750 & 90 \\
\hline 14 & 55 & 750 & 150 \\
\hline 15 & 55 & 750 & 220 \\
\hline 16 & 55 & 850 & 90 \\
\hline 17 & 55 & 850 & 150 \\
\hline 18 & 55 & 850 & 220 \\
\hline 19 & 65 & 650 & 90 \\
\hline 20 & 65 & 650 & 150 \\
\hline 21 & 65 & 650 & 220 \\
\hline 22 & 65 & 750 & 90 \\
\hline 23 & 65 & 750 & 150 \\
\hline 24 & 65 & 750 & 220 \\
\hline 25 & 65 & 850 & 90 \\
\hline 26 & 65 & 850 & 150 \\
\hline 27 & 65 & 850 & 220 \\
\hline
\end{tabular}

\section{Undercut}

The occurrence of an "Undercut" is a result of the ability of the etchant to etch both laterally and vertically once it has permeated through a feature or aperture in the photoresist. This results in after etching a wider feature than that in (Allen et. al, 2004) (Saraf \& Sadaiah, 2016) the photoresist stencil as shown in fig. 2 [20-23]. The design of the photo-tool artwork subsequently requires compensation (Allen et. al, 2004).

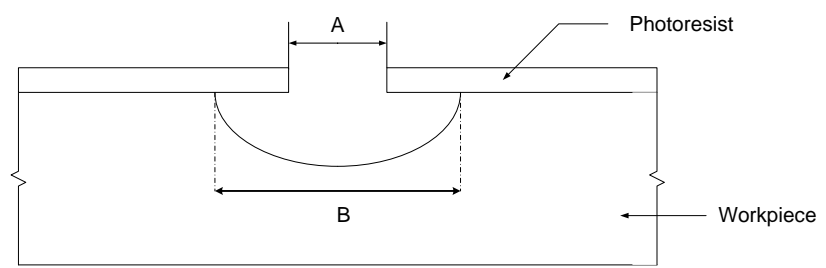

Fig. 2. Undercut $=1 / 2(B-A)$

\section{Results and Discussion}

The analysis of experimental data was performed in order to determine the effect of temperature, time and concentration on the magnitude of undercut and surface roughness. The analysed results are presented using main effects and interaction plots.

\subsection{Statistical analysis of the undercut $(U c)$}

The summary of analysis of variance (ANOVA) is shown in Table 3. It is observed that the factor undercut has a significant effect at $95 \%$ confidence interval as evident from ANOVA Table 3.

From the fig. 3, it is clear that as the temperature increases the undercut increases. This is because; in ferric chloride the molecules are in constant motion. The kinetic energy and the velocity of ferric chloride molecules increase with the temperature. Every reaction usually requires collisions between reactant molecules or atoms. The formation of bonds requires atoms to come close to one another. New bonds can form only if the atoms are close enough together to share electrons. Some collisions are not successful. These are called ineffective collisions. The particles simply hit and then rebound. Collisions that lead to products are called effective 
collisions. An effective collision must happen with a great enough speed, energy and force to break bonds in the colliding molecules.

Collisions between molecules will be more violent at the higher temperatures. The higher temperature means higher velocities. This means that there is a less time between the collisions. The frequency of collisions increases with increase in the temperature. The increased number of collisions and the greater violence of collisions results in more effective collisions. Thus the undercut increases. From this, it is clear that it can be to possible decrease the undercut by increasing the temperature and which can be increased by lowering the temperature.

Table 3 ANOVA Summary table for Undercut, Uc

\begin{tabular}{|c|c|c|c|c|c|c|}
\hline Control factor & $\begin{array}{l}\text { Degree of } \\
\text { freedom }\end{array}$ & Sum of Square & Variance & F-ratio & $p$-value & $\begin{array}{l}\text { Significant } \\
\text { (Yes / No) }\end{array}$ \\
\hline Temp. $\left({ }^{0} \mathrm{C}\right)$ & 2 & 0.221369 & 0.221369 & 42.66 & 0.000 & YES \\
\hline $\begin{array}{l}\text { Conc. } \\
\text { (gm / lit) }\end{array}$ & 2 & 0.102968 & 0.102968 & 19.84 & 0.001 & YES \\
\hline Time (Sec.) & 2 & 0.201020 & 0.201020 & 38.74 & 0.000 & YES \\
\hline Temp. * Conc. & 4 & 0.066290 & 0.066290 & 6.39 & 0.013 & YES \\
\hline Temp.* Time & 4 & 0.083364 & 0.083364 & 8.03 & 0.007 & YES \\
\hline Conc. ${ }^{*}$ Time & 4 & 0.005307 & 0.005307 & 0.51 & 0.730 & $\mathrm{NO}$ \\
\hline Error & 8 & 0.020758 & 0.020758 & & & \\
\hline Total & 26 & 0.701077 & & & & \\
\hline $\mathrm{S}=0.0509384 \%$ & & $\mathrm{R}-\mathrm{Sq}=97.04 \%$ & & \multicolumn{3}{|c|}{ R-Sq(adj. $)=90.38 \%$} \\
\hline
\end{tabular}

From fig. 3, it is also clear that with increase in concentration undercut also increases. This is because concentration increases means the number of molecules for reaction is also increases. As molecules for the collision increase, the reaction rate also increases. Therefore undercut is increases with increase in concentration.

It is observed from the main effects plots in fig. 2 that the optimum etching performance parameters for the undercut were observed at a temperature of $45^{\circ} \mathrm{C}$, a concentration of $650 \mathrm{~g} / \mathrm{l}$ and etching time of 90 minutes.

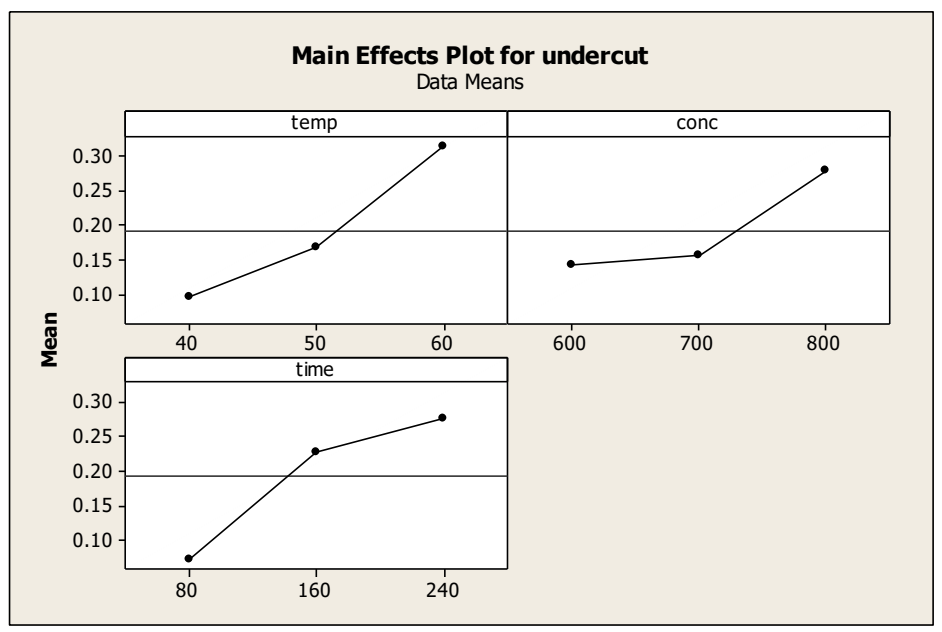

Fig. 3. Main effect plots for undercut Uc (mm) 


\section{Conclusions}

From the experimental investigations based on full factorial method and the analysis of the results, the following conclusions are drawn.

-It is observed from the ANOVA, the input variables time, Concentration and temperature have statistically significant effects on the undercut.

-The above discussion confirmed the validity of the full factorial methodology for enhancing the etching performance and optimizing the etching parameters. The undercut is greatly improved by this approach.

-Minimum Undercut (Uc) was observed at the temperature of $45^{\circ} \mathrm{c}$, etchant concentration 650 gm/litre and etching time 90 minutes.

\section{References}

[1]. I Allen, D.M. The state of the art of photochemical machining at the start of the twenty-first century. Proceedings of the Institution of Mechanical Engineers, Part B: Journal of Engineering Manufacture, 2003, 217(5), pp.643-650.

[2]. Muhl, J. and George. Direct printing of etch masks under computer control. Int. J. Mach. Tools Manufacture, 1995, 26(2), pp.333-337.

[3]. Wei, W.; Di, Z.; Allen, D.M.; Almond, H.J.A. Non-traditional machining techniques for fabricating metal aerospace filters. Chinese Journal of Aeronautics, 2008, 21(5), pp.441-447.

[4]. Roy, R.; Allen, D.; Zamora, O. Cost of photochemical machining.Journal of Materials Processing Technology, 2004, 149(1), pp.460-465.

[5]. Ferrari, M.; Cagidiaco, M.C.; Borracchini, A.; Bertelli, E. Evaluation of a chemical etching solution for nickel-chromium-beryllium and chromium-cobalt alloys. The Journal of prosthetic dentistry, 1989, 62(5), pp.516-521.

[6]. Tehrani, A.F.; Imanian, E. A new etchant for the chemical machining of St304. Journal of materials processing technology, 2004, 149(1), pp.404-408.

[7]. Cakir, O. Copper etching with cupric chloride and regeneration of waste etchant. Journal of materials processing technology, 2006,175(1), pp.63-68.

[8]. Allen, D.M.; Almond, H.J. Characterisation of aqueous ferric chloride etchants used in industrial photochemical machining. Journal of Materials Processing Technology, 2004, 149(1), pp.238-245.

[9]. Katharine B. Small, Guide to Etching Speciality Alloys, Advanced Materials \& Process/Feb 2008

[10]. Roy, R.; Allen, D.; Zamora, O. Cost of photochemical machining.Journal of Materials Processing Technology, 2004, 149(1), pp.460-465.

[11]. Stanford, C.M. Surface modifications of dental implants. Australian dental journal, 2008, 53(s1), pp.S26-S33.

[12]. Patil, D.H. and Mudigonda. S. The Effect of the Rolling Direction, Temperature, and Etching Time on the Photochemical Machining of Monel 400 Microchannels. Advances in Materials Science and Engineering, 2016.

[13]. Mudigonda. S. and Patil, D.H., 2015, June. Some Investigations on Surface Texturing on Monel 400 Using Photochemical Machining. In ASME 2015 International Manufacturing Science and Engineering Conference (pp. V001T02A045-V001T02A045). American Society of Mechanical Engineers.

[14]. Saraf, A.R., Sadaiah, M. and Devkare, S., 2011. Optimization of photochemical machining. International Journal of Engineering Science and Technology, 1(3), pp.7108-7116.

[15]. Saraf, A.R., Misal, N.D. and Sadaiah, M., 2012. Mathematical modelling and optimization of photochemical machining. In Advanced Materials Research (Vol. 548, pp. 617-622). Trans Tech Publications. 
[16]. Saraf, A.R. and Sadaiah, M., 2013. Application of artificial intelligence for the prediction of undercut in photochemical machining. International Journal of Mechatronics and Manufacturing Systems. 2015 6(2), pp.183-194.

[17]. Saraf, A.R. and Sadaiah, M., 2011. Photochemical Machining of SS304,„Int. Journal of Advances in Science and Technology. 2015 3(6), pp.71-85.

[18]. Saraf, A.R., Misal, N.D., Sadaiah, M., Chavan, A.M. and Sathe, S.S., Some Investigation on Photochemical Machining of Phosphor Bronze.

[19]. Saraf, A.R. and M.Sadaiah. Photochemical Machining of SS316L, Manufacturing Technology Today, 2012 Vol.11 ,No.7, pp 5-9,

[20]. Saraf, A.R. and Sadaiah, M. "Magnetic field assisted photochemical machining of SS316L" accepted in the journal "Materials and Manufacturing Processes" Taylor and Francis. ( ID: 1198014 DOI:10.1080/10426914.2016.1198014)

[21]. Saraf, A.R. and Sadaiah, M. "Photochemical Machining of a Cardiovascular Stent" accepted in the journal "Materials and Manufacturing Processes" Taylor and Francis. (ID: 1198025 DOI: $10.1080 / 10426914.2016 .1198025)$

[22]. Saraf, A.R. and Sadaiah, M. "Predictive Modeling of Undercut in Photochemical Machining", Proceedings of 3rd International conference on recent trends in Engineering and Technology (ICRTET 2014), pp.470-474

[23]. Saraf, A.R., P.M.Shinde and M.Sadaiah, "Multi-objective optimization of photochemical machining by using Grey Relational analysis", $2^{\text {nd }}$ International Conference on Advanced Manufacturing and Automation (INCAMA-2013), Kalasalingam University, Krishnankoil, Tamil Nadu, India. 